\title{
Growth Inhibitory Effect of Fibroblast Growth Factor Peptide Antagonist on Mouse Model Breast Tumor through ERK/MAPK and PI3K/AKT Signaling Pathways
}

mehrzad jafarzadeh ( $\nabla$ jafarzadehmehrzad@gmail.com )

Iran University of Medical Sciences

Kazem Mousavizadeh

Iran University of Medical Sciences

Mohammad hashemi Bahremani

Shahid Beheshti University of Medical Sciences School of Medicine

S.mohsen Asghari

University of Guilan

Research article

Keywords: peptide, ERK/MAPK, AKT/PI3K, Breast cancer, Tumor

Posted Date: October 16th, 2019

DOI: https://doi.org/10.21203/rs.2.16080/v1

License: (c) (i) This work is licensed under a Creative Commons Attribution 4.0 International License.

Read Full License 


\section{Abstract}

Background In the majority of cancers, metastasis of tumor cells is main cause of treatment failure. The current research investigated the effectiveness basic fibroblast growth factor (bFGF) peptide developed to inhibit tumor growth in $4 \mathrm{~T} 1$ metastatic breast cancer through the PI3K/AKT and ERK/MAPK signal transduction pathways. In BALB/c mice, the tumor was induced through 4T1 tumor graft. Administration of the peptide was done one time a day at various doses of $1,2.5$, or $10 \mathrm{mg} / \mathrm{kg}$ over 14 days. After two weeks, the designed peptide injected .After the treatment period, the mice underwent surgery, and tumors were used for the Immunohistochemistry, Apoptosis, and western blot examinations.

Results Based on one-way ANOVA and $p \leq 0.05$, findings showed that the P-AKT and $p$-ERK contents in tumors treated with peptide reduced in two mentioned signaling pathways and the peptide injection were effective in reducing or inhibiting tumor growth.

Conclusion Our findings showed that in the two signal transduction pathways, the P-AKT and p-ERK levels were significantly different from the negative control group.

\section{Background}

According to statistics, breast cancer is the mostly prevalent malignant condition and the major healththreating factor and mortality among women. [1].Cancer is a multi-stage procedure including irretrievable genetic alterations in stem cells and, subsequently, clonal multiplication of these cells, and ultimately, the developing an incursive phenotype with a metastatic cancer. Cancer has to be prevented or treated at various steps of the procedure, by the use of differing phenotypes [2]. Today, common treatments are surgery, chemotherapy, and radiotherapy [3]. In most of cancers, the metastasis of cancer cells is main cause of treatment failure [4]. Despite the fact that operation and radiotherapy are useful for local tumor treatment, they are not necessarily effective in handling metastatic cancers. In such cases, the treatment is often based on chemotherapy; yet, chemotherapy application comes with practical limitations because of its toxic fallout sat high dosages.

As a result, peptide therapy has become a widely used treatment in the world $[5,6]$. In the current trial, the impact of designed peptides was examined on growing 4T1-MCT with of high invasiveness and metastasis. All protocols were approved by the experimental animals of the National Ethics Committee in Biomedical Research of the Islamic Republic of Iran.

\section{Methods}

\section{Synthetic peptide}

Using high-performance liquid chromatography, the peptide synthesis and purification were performed to a $90 \%$ purity, followed by analyzing through the matrix-assisted laser desorption/ionization time-of-flight mass spectrometry, which were ultimately verified by electrosprayionization mass spectrometry (ESI-MS). 
A peptide was constructed with the sequence of CGGSGLPLGHIKC according to that of basic fibroblast growth factor (bFGF2) [10], manufactured by the Shine Gene Biotechnologies Inc. (Shanghai, China).

\section{Metastatic breast cancer modeling}

Weak metastasis in mice can be induced by the human tumor cells, and unanticipated outcomes may ensue in case of metastasis occurrence. In spite of this, murine tumor renders more effective metastasis and features similar to those observable in cancerous patients [7]. Tumor in animals with the normal immune system can be analyzed by conditions provided by this type of tumor. The pivotal contribution the immune system to the emergence and development of cancer [8] necessitates designing models for application in the perfect immune of mice to assess medicines and peptides. One of the several breast cancer cell lines is the 4T1 cell line, which can effectively induce metastasis to areas engaged in human breast cancer [9].BALB/c mice are the laboratory- bred strain of albino mice specially used for the study cancer. Original BALB/c, and the 4T1 breast cancer cell lines wereprocured from the Pasteur Institute of Iran, and grown in a glucose-rich DMEM culture medium with $10 \%$ fetal bovine serum, and $5 \%$ inessential amino acids, as well as penicillin and streptomycin antibiotics, and place in an incubator at $37^{\circ} \mathrm{C}$ under $5 \%$ carbon dioxide environment. BALB/c was preserved at a $24{ }^{\circ} \mathrm{C}, 12 \mathrm{~h}$ light/ $12 \mathrm{~h}$ dark photoperiod, and sufficient moisture with adequate food and water for 5-7 weeks. The mice were retained in polycarbonate cages with lace doors.

This research was carried out in accordance with the ethical guidelines of research on the experimental animals of the National Ethics Committee in Biomedical Research of the Islamic Republic of Iran.

\section{Tumor implantation and antitumor activity}

Breast cancer was induced by two methods of $4 \mathrm{~T} 1$ cell injection and cancer tissue transplant. In cancer cell injection procedure, the site of injection in rats was sterilized by cotton and alcohol. In day zero, all mice were hypodermically injected cancer cells $\left(4 \mathrm{~T} 1 ; 1 \times 10^{6}\right.$ cells $/ 500 \mu \mathrm{l}$ or $1 \times 10^{5}$ cells/50 $\left.\mu \mathrm{l}\right)$ ) at a place targeted next to the lower most right side breast gland. Following 2 weeks, the mice underwent euthanasia and surgery (10). The "Euthanasia" defined as"good death" aiming at providing a quick, painfree, non-stressful death. A fast unconsciousness is induced by carbon dioxide. After which death occurs. The cage volume should be replaced by $\mathrm{CO} 2$ flow rate at $10 \%$ to $30 \%$ per minute. The animals should be easily observable in the euthanasia chamber. The only suggested sour of $\mathrm{co} 2$ are cylinders containing compressed co2 gas because they enable the control of gas inflow into the induction chamber.

Then, the tumor was incised into sections of $<0.3 \mathrm{~cm}^{3}$ and hypodermically implanted into the mice's right flanks after anesthetizing the animals with ketamine $(100 \mathrm{mg} / \mathrm{kg})$ and xylazine and xylazine $(10 \mathrm{mg} / \mathrm{kg})$.

Peptide treatment was applied upon reaching a tumor size of 0.5 to $1 \mathrm{~mm}^{3}$ after a 2 weeks period of tumor implantation. The tumor volume was evaluated daily by a digital Vernier caliper according to the formula: Volume $=$ shortest diameter ${ }^{2} \times$ longest diameter $\times 0.52(10)$. 
The BALB/c mice having 4T1- MCT were then used to evaluate the antitumor activities of the peptide. To this end, rats were assigned at random to four groups of 10 mice each ( $n$ total $=40$ mice).

\section{Peptide Administration}

\section{bFG suppresses the growing and metastasis of a MCT model}

bFG antitumor efficacy was investigated in the murine 4 T1 MCT model, and having built the solid tumors (tumor volume $\sim 400 \mathrm{~mm} 3$ ), intraperitoneal (i.p.) administration of the peptide was done one time daily at various doses of $1,2.5,10 \mathrm{mg} / \mathrm{kg}$ over 2 weeks.

On the $28^{\text {th }}$ day, the tumor mean volume showed a significant increase in the phosphate buffered saline (PBS) treatment group compared to that at different doses of bFG $1 \mathrm{mg} / \mathrm{kg}, 2.5 \mathrm{mg} / \mathrm{kg}$, and $10 \mathrm{mg} / \mathrm{kg}$ groups $(P<0.001)$. This demonstrates that the $b F G$-caused tumor reversion had no associations with dose- response between the dosages of 1 and $10 \mathrm{mg} / \mathrm{kg}$. No mortality was recorded in animal groups experienced solid tumors throughout the tests, illustrating that bFG is not toxic at dosages used in this trial. Also, we did not see any decrease in the animals' weight in bFG-treated groups; in fact, weight gain had been observed.

A highlighting prerequisite for tumor cell transport via the circulations and metastasis is believed to be tumor angiogenesis, and tumor angiogenesis inhibition has been revealed to be suppressed for tumor metastasis. This experiment aimed to examine whether or not bFG was also capable of blocking the metastasis of malignant murine mammary tumor cells (4 T1 cells).

\section{Viability analysis using MTT method}

MTT is a method based on the colorimetric for determining survivability and cell toxicity of materials on the basis of recovering yellow soluble crystals of 4, 5 Dimethyl thiazole, 2-5Diphenyl tetrazolium bromide (MTT) by mitochondrial succinate dehydrogenase enzyme of viable cells and formation of formazan purple solution crystals. Using measurement of optical absorption in 570nm usingUltraviolet-Visible Spectrophotometer and using standard curve, a number of viable cells can be determined. The Proliferation of $4 \mathrm{~T} 1$ cells. The antagonistic activity of the peptide was examined on $4 \mathrm{~T} 1$ cells by the use of different peptide levels $(50-600 \mathrm{ng} / \mathrm{ml}$ ) and $20 \mathrm{ng} / \mathrm{ml}$ of rhbFGF. Seeding4T1 cells was done in $96-$ well plates with $5 \times 10^{3}$ cells per well. After incubation of well-plates under a temperature of $37^{\circ} \mathrm{C}$ and $5 \% \mathrm{CO} 2$, cells were rinsedby PBS and kept serum-starving in serum-free DMEM with $0.02 \%$ FBS within $24 \mathrm{~h}$. Next, cells underwent treatment with peptides of serial dilutions and $20 \mathrm{ng} / \mathrm{ml} \mathrm{bFGF}$ for $24 \mathrm{~h}$. Then, the produced formazan was converted to solution via adding a solvent like Dimethylsulfoxide (DMSO). Finally, solution absorption was read in wavelength of $570 \mathrm{~nm}$ to determine number of survived cells.

\section{BFG binding assays}

To evaluate the competitive binding of BFG protein, 4 T1 cells were first grown in DMEM in 96-well plates (5000 cells/well) and then subjected to incubation in $5 \% \mathrm{FBS}$ at $37{ }^{\circ} \mathrm{C}$ during nighttime. Following $24 \mathrm{~h}$, 
the media were altered to the DMEM with no FBS, and all cells, excluding the control group cell, were treated with bFG at $37^{\circ} \mathrm{C}$ overnight. At ambient temperature over 5-10 min, cells were fixed using paraformaldehyde $4 \%$ and rinsed with PBS. Then, the PE-conjugated anti-bFGFR1 antibody was added, and cells were made permeable using PBS $+0.3 \%$ Triton $X-100$, blocked with $10 \%$ normal goat serum and BSA 1\%/PBST at room temperature for 20 minutes.

Cells were stained with 4', 6-diamidino-2-phenylindole (DAPI; Invitrogen, Carlsbad, California, USA) (1 $\mu \mathrm{g} \cdot \mathrm{mL}-1$ ) with FITC-secondary anti-rabbit antibodies, and subjected to treatment using propidiumiodide (Pl; Sigma Aldrich, USA, P4170) $(1 \mu \mathrm{g} \cdot \mathrm{mL}-1)$ for nuclear staining. They were then stained by fluorescence microscopy in the blue light (DAPI; Invitrogen, Carlsbad, California, USA; $1 \mu \mathrm{g} \cdot \mathrm{mL}-1$, nuclear staining), and prior to undergoing analysis with the $\mathrm{NIH}$ ImageJ plug-in, they were combined (http:// imagej.nih.gov/ij/). Error bars indicate the standard error of the mean (SEM) of estimations made on six samples in each group, and scale bars are $20 \mu \mathrm{m}$. A. After 24, 48, and 72 hours, the effects of BFG on the 4 T1cells proliferation were quantified by 3-(4, 5-dimethyl thiazolyl-2)-2, 5-diphenyltetrazolium bromide (MTT) (Sigma, St. Louis,Missouri, USA) experiments as meticulously clarified formerly with slight alterations. Using the ELISA reader (Space Fax 2100, A wareness,USA), absorbance was read at $570 \mathrm{~nm}$ with background deduction of $630 \mathrm{~nm}$.

\section{Immunohistochemistry}

Due to immunohistochemical (IHC) analysis, excised tumor tissues were fixated in formalin (4\%), imbedded in paraffin, segmented, and exposed to staining by hematoxylin-eosin (H\&E). Heat-activated epitope recovery in a buffer at $\mathrm{pH} 9.0$ was doneprior to immunohistochemistry (IHC).

IHC staining was carried out followed by the formalin-fixated paraffin imbedded segments to measure different proteins involved in various procedures such as CD31 and CD34 proteins for assigning MVD and Ki67 to specify the proportion of Ki67-positive cells, and also P53 and Bcl-2 to clarify the fraction of apoptotic cells in relation to the whole cells.

Dead cells were stained by TUNEL (terminal deoxynucleotidyltransferase nick-end labeling), then by developing the enzyme in diaminobenzidine (DAB) (Invitrogen, Carlsbad, California, USA) recognition and counter-staining with hematoxylin. The samples were analyzed using microscopy (Olympus BX-51, Japan), and having analyzed five random tissue samples under scale bars 100 and $20 \mu \mathrm{m}$, many positive cells were determined and quantitatively analyzed by ImageJ software.

\section{Apoptosis Examination with Tunel Kit}

Apoptosis was identified through the in situ Cell Death Detection Kit, Roche-11684817910. In brief, the sections were deparaffinized and dehydrated, and then rinsed with distilled water. The tissues were stored in a solution of proteinase $\mathrm{K}(20 \mathrm{mg} / \mathrm{mL})$ at room temperature for $15 \mathrm{~min}$. Endogenous peroxidase activity was also blocked through incubation in $3 \mathrm{~mL} / \mathrm{L}$ solution of hydrogen peroxide/methanol for 30 min at $37^{\circ} \mathrm{C}$. Sections were exposed to incubation with terminal deoxynucleotidyltransferase at $37^{\circ} \mathrm{C}$ for 
60 min. Then, digoxygenin-conjugated deoxyuridine triphosphate (dUTP) was added to the 3'-OH ends of the fragmented DNA molecule. Anti-dioxygenin peroxidase antibody was used to detect the labeled nucleotides. The sections were stained with diaminobenzidine and hematoxylin was used for background staining.

\section{Western blot}

In the current research, the impacts of the peptide were investigated on PI3K/AKT and ERK/MAPK signaling pathways.To obtain homogeneous tumor tissue, approximately $150-200 \mathrm{mg}$ of the tumor tissue was powdered in a mortar, lubricated in RIPA buffer ( $50 \mathrm{~mL}$ of Tris hydrochloride, $150 \mathrm{mM}$ sodium chloride, $1 \% \mathrm{NP}-40$, sodium deoxycholate, $10 \%$ sodiumdodecyl sulfate, $0.01 \mathrm{M}$ phenylmethylsulfonyl fluoride, emulsifiable EDTA) with a ratio of 1:5, and completely homogenized. The solution was then stored at $4{ }^{\circ} \mathrm{C}$ for $30 \mathrm{~min}$ and then underwent centrifugation at $14,000 \mathrm{rpm}$ at $4{ }^{\circ} \mathrm{C}$ for $15 \mathrm{~min}$. The supernatant was collected and kept at $-80^{\circ} \mathrm{C}$. The Protein contents of specimens were assessed using the Bradford technique based on the Bovine serum albumin.

To perform western blot, $20 \mu \mathrm{g}$ of protein was loaded into each well, and the protein was isolated using the SDS PAGE technique with $12.5 \%$ gel.The isolated proteins were relocated to PVDF membrane with a pore size of $0.45 \mu \mathrm{m}$. Then, the membrane was moved to a solution that contained $50 \mathrm{mM}$ Tris-HCl buffer, $0.1 \%$ TWEEN 20 Detergent, $150 \mathrm{Mm} \mathrm{NaCl}$, and 5\% skimmed milk and stored for 1.5 hours. Then; the membrane was stored in an initial antibody solution with the concentration of $1 \mu \mathrm{g} / \mathrm{mL}$ overnight, diluted in a buffer containing $1 \%$ BSA and $2 \%$ skimmed milk. After rinsing the membrane, it was subjected to the secondary HRP to remove the non-attached antibodies and then rinsed again. Protein expression was measured using the ECL method. The membrane was exposed to the radiographic film and the bands appeared by processing the films in the darkroom. Then, the bands density was measured using densitometry.

\section{Statistical analysis}

Data were analyzed statistically and the charts were drawn by the Prism software (Version 6.00). Data are expressed as mean \pm SEM. One-way ANOVA and then Tukey's posthoc test was employed to verify statistically significant differences for manifold comparisons. Two-way repeated measures ANOVA ensued by Tukey's post-hoc test were applied for treatment effectiveness in influencing tumor development with a statistical probability of $\mathrm{P}<0.05$.

\section{Results}

\section{Inhibition of tumor growth}

To evaluate the antitumor impact of bFGF, inhibition of murine 4T1 cell line induced MCT growth was examined in BALB/c mice administration of the peptide in three dosages $1,2.5$, and $10 \mathrm{mg} / \mathrm{kg} / \mathrm{day}$. Comparisons were made for the findings resulted from peptide-treated samples with oneanother and with 
the PBS-treated control group. Obtained data from tumor size were collected with prism software and examined by prism and one way ANOVA test by consideringp $\leq 0.05$ as significance level (FIG1).

\section{Cell multiplication}

According to the findings, treating the samples by peptide within $24 \mathrm{~h}$ led to a reduction of $4 \mathrm{~T} 1 \mathrm{cell}$ multiplication dose-dependently (bFGF $20 \mathrm{ng} / \mathrm{ml}$, Peptide 50,100,200,400,600 ng/ml). Consequently, the peptide intervene the inducing impact of rhbFGF acting as its antagonist (FIG. 2).

\section{bFG reduced cell growth, microvascular density, and induced apoptosis in the MCT model}

To detect the therapeutic effect of bFG and its powerful mechanisms behind that, sections embedded in paraffin sampled from 4 T1 MCTs (28 d post-implantation) were stained and examined for possible changes concerning the tumor cellsto evaluate microvascular density (MVD), tumor cell growth, and apoptosis changes. In breast tumors, MVD was utilized by the number of CD31- and CD34-stained microvessels to determine the bFG antiangiogenic features. Various dosages of bFG (1 to $10 \mathrm{mg} / \mathrm{kg}$ ) as treatment led to 5 and 7 -fold declines in the expression of CD31, and 5 and 8-fold drops in the expression of $C D 34$, in comparison to the PBS-treated control groups $(P<0.05, P<0.01)$.

Immunohistochemical assessments also appeared that tumor cell multiplication can be inhibited by bFG, as it is vividly shown by a $65 \%$ decrease in Ki67-positive cells as opposed to the control mice $(P<0.01)$. To evaluate whether or not the faulty tumor proliferation was linked to the progression of apoptosis in peptide-treated mice group and inside tumor tissue, MCT paraffin embedded pieces were stained by TUNEL, which is an indicator of the late apoptosis, in addition to the anti-Bcl-2 and anti-p53 antibodies as the primary apoptosis biomarkers).

In peptide-treated mice, the percentage of TUNEL-positive cells was substantially greater than that in the control mice $(P<0.001)$. In fact, the apoptogenic impact of bFG was proved by p53 and Bcl-2 staining. Even though, in peptide-treated groups, a small amount of cells underwent staining with anti-Bcl-2 antibody, a significant amount of $\mathrm{Bcl}-2$-positive cells was observable tumors in the control animals ( $\mathrm{P}$ $<0.001)$. Moreover, p53-positive cells amplified significantly in peptide-treated tumors in comparison with PBS-treated groups $(P<0.001)$.

The histopathological experiments that we have done, indicated that bFG considerably can inhibit tumor MVD and cell growth, and stimulated apoptosis in the tumor cells as well. In line with the modification of cell multiplication and apoptotic changes, in the bFG-treated tumors as opposed to PBS-treated controls, H\&E staining disclosed potential modification of cell morphology. It is noteworthy that the immunohistochemical findings for 1 and $10 \mathrm{mg} / \mathrm{kg} /$ day dosages were not significantly different.

\section{Apoptosis measurement}

Treatment of 4T1 cells in cancerous mice with a designed fibroblast growth factor peptide confirmed the induction of apoptosis in these cells. The nuclei of the treated cells had a brown color compared to the 
control group. This study aimed to identify engineered bFGF antagonist peptide to inhibit breast tumor angiogenesis (FIG3).

\section{Western blot}

Expression of p-AKT/AKT and p-ERK1/2/ERK1/2 levels in MCT was examined through treatment by bFGF antagonist peptide. Comparative amounts of p-AKT/AKT and p-ERK1/2/ERK1/2 were assessed with ImageJ. The results of Western blot demonstrated that the engineered peptide led to significant reductions in the expression of the phosphorylated forms of ERK, AKT (P $\leq 0.05)$ (FIG5). However, changes in the ERK and AKT expression levels had no statistical significance.

\section{Discussion}

Despite frequent studies, the exact mechanism for the antagonistic inhibitory and anti-cancer functions of peptides has not yet been identified. A Peptide can affect the signal transduction pathways, which include phosphoinositide 3-kinase (PI3K) and AKT (protein kinase B), and subsequently, the proliferation, differentiation, apoptosis, and metastasis processes [11-14]. The PI3K/AKT pathway is involved in simultaneous control of metabolism and cell growing and proliferation in healthy and malignant cells. In many types of cancers, the components of this pathway increase in size or function, and this is one of the most important reasons for increasing the survival rate and reducing the death of cancer cells [15, 16]. Stimulation of some cell surface receptors, such as tyrosine kinase or $\mathrm{G}$ protein-coupled receptors, due to binding of ligands such as growth factors and insulin, results in phosphorylation and stimulation of the PI3K enzyme and subsequent phosphorylation and activation of AKT as a central kinase in this pathway [15-17]. Active AKT leads to the phosphorylation of some compounds in the regulatory pathways of cell proliferation, differentiation, and survival, such as apoptotic proteins and transcription factors, which ultimately lead to inhibition of apoptosis and increased cell proliferation, growth, and survival $[15,18]$.

The MAPK/ERK is a signaling pathway that begins with tyrosine kinase receptor ultimately reaching the DNA in the cell's nucleus and activating the genes involved in cell division. The MAPK/ERK pathway is connected to other pathways, such as PI3K/AKT, and activates this pathway. This pathway starts with tyrosine kinase membrane receptors of the ErbB EGFR family (fibroblast growth factor) and PDGFR (platelet-derived growth factor). After binding of a ligand to the receptor, the receptor forms a dimer and recalls Grb2 and SOS enzymes. These two enzymes convert GDP to GTP in the RAS enzyme. Once the RAS-GTP is formed, the enzyme is placed on the inner surface of the cellular membrane and the MAPK/ERK cascade is activated. The MAPKinase proteins are phosphorylated and activated, which in turn activate parallel pathways, such as PI3K. It can also pass through the nucleus membrane and activate the transcription factors, such as G-myc, and cause the expression of the cell division gene. Erk induces epithelial cells through down-regulation of the Bim, a proapoptotic protein, which does not have the cytotoxic properties of Bax. The reduction of the Erk signal transduction pathway inactivates the 
integrin and reduces the expression of EGFR, which itself results in up-regulation and ultimately apoptosis.

A compound activated by the PI3K/AKT pathway is the nuclear factor kappa $\beta$. This nuclear transcription factor is a heterodimer composed of P50-P65 proteins in the cell cytoplasm that enters the nucleus after activation and changes the gene expression. The enzymatic complex of the kinase inhibitor of kappa- $\beta$ is one of the compounds phosphorylated by AKT, leading to NF-K $\beta$ activation. The genes activated by this transcription factor play a role in cell cycle regulation, proliferation, survival, inflammation, and metastasis. Increased activity of these factors in cancer cells is one of the most important mechanisms of cell resistance to pharmacotherapy with ionizing radiation therapy [19-23].The mTOR protein complex with its kinase activity plays a role in regulating cell growth, proliferation, survival, transcription, and protein synthesis. Increased expression and activity of this complex have been observed in many types of cancers. One of the activation pathways for this enzyme complex is its phosphorylation by phospho-AKT, due to the PI3K/AKT pathway activity $[24,25]$.

\section{Conclusion}

The present cancer therapy approaches have been ensued by multiple fallouts, such as injury to unaffected cells and drug resistance, resulting in its recursion. Accordingly, it is necessary to employ novel curative methods with stronger impacts, weaker toxicity, and fewer adverse effects, including treatment by peptides. Folkman (1990) was one of the pioneer investigators who proposed the suppression of tumor blood vessel development for cancer therapy[26]. Concerning the great selectivity and affordable prices of peptides, these compounds are a very appropriate option with less fallouts and lesser toxic activity[27]. Khumalo et al. (2005) supported discovery and identification of new methods for cancer treatment to increase sensitivity of cancer cells, since cancer resistance to conventional treatments have increased [28]. The first FDA-Approved anti-angiogenic drug was reported by Choren et al. (2007) which could be used to treat solid tumors and inhibited endothelia growth factor [29]. Stup et al. (2010) reported that combined chemotherapy could show synergistic effects in cancer treatment [30]. Anderson et al. (2010) stated that combination of chemotherapy and radiotherapy would present synergic effects [31]. In 2012, Li et al. (2012) introduced a peptide with the ability to not only inhibit bFGF proliferation in cancer cells of breast but also to stimulate cell-cycle detention in the G0/G1 phase of the cell cycle [32]. Macrovich et al. (2015) suggested the clinicians to make use of new techniques for drug delivery as well as development of methods with synergistic effects besides application of antiangiogenic treatment modalities in preclinical animal studies [33].

Antiangiogenic therapies are popular, cell multiplication; viability, intrusion, and metastasis are assaymarks of carcinogenic procedure. Signal transduction alteration can lead to uncontrolled cell proliferation. Several signaling pathways are vital to maintain normal human physiology including phosphatidylinositol 3-kinase (PI3K)/AKT/mammalian target of rapamycin (mTOR) and the Raf/mitogen-activated and extracellular signal-regulated kinase (MEK)/extracellular signal-regulated kinase (ERK). These signaling pathways are dysregulated in many human cancers such as breast cancer 
(BC). PI3K/AKT/mTOR and Raf/MEK/ERK cascades are interrelated with cross-talks and several convergence points, and feedback loops which are proven by both in vitro and in vivo data. Mutations in Raf/MEK/ERK and PI3K/AKT/mTOR pathways may be present simultaneously. Signaling may be maintained in case of one pathway inhibition; by means of signaling through the reciprocal pathway. Many studies are already underway aiming either one of the pathways or both pathways in patients with breast cancer. Considering the critical physiological functions of PI3K/AKT/mTOR and Raf/MEK/ERK signaling pathways, monitoring of toxicity profile of dual pathway targeting in of great importance [34]. Key role of ERK1/2 signaling in proliferation induction is well known as well as its contribution to the expansion and progress of cancer. Consequently, it is of no surprise that ERK1/2 cascade inhibitors such as vemurafenib and trametinib $[35,46]$ are considered among anticancer drugs.ERK1/2 cascade, as an intracellular signaling pathway, includes sequential phosphorylation and stimulation of Raf or other MA3Ks, MEK1/2, ERK1/2 and many downstream MAPKAPKs. This cascade is responsible for many cellular processes, especially cell proliferation and differentiation [37-39]. Dysregulation of this pathway, as a central regulatory pathway, has been shown to have a function in cancer pathophysiology [40, 41]. In 2018, Plotnikov et al. (2018), reported a proof of concept that ERK1/2 nuclear translocation may be targeted in the treatment of various cancers related to ERK1/2 [42].

Our research examined the influence of designed peptides on the development of 4T1 MCT with high invasion and metastasis. The findings indicated reversion of tumor development, which was significantly different between the negative control and peptide groups.

Our results indicated the effectiveness of peptide therapy and showed that the P-AKT and p-ERK contents in tumors exposed to treatment with peptide reduced in two mentioned signaling pathways.

\section{Abbreviations}

FGF: fibroblast growth factors

PI3K/AKT: Phosphatidylinositol-3-Kinase and Protein Kinase B

ERK/MAPK: Extracellular Signal-Regulated Kinase Mitogen- Activated Protein Kinase

TUNEL: Terminal deoxynucleotidyl transferase dUTP nick end labeling

DMEM: Dulbecco's modification of Eagle medium

DMSO: Dimethyl sulfoxide

$B A L B / C$ : albino, laboratory-bred strain of the house mouse

\section{Declarations}

\section{Acknowledgments}


The author acknowledge with thanks for vice chancellor for research \& technology of the Iran University of Medical Sciences .

\section{Funding}

This study was conducted with the financial support vice chancellor for research \& technology of the Iran University of Medical Sciences (contract number 28093-87-01-95). MJ designed and performed the experiments, participated in the interpretation of data, and wrote manuscript. SMA, MJ, KM, MHB performed the biological experiments, interpreted the data, and wrote the manuscript.

\section{Availability of data and materials}

All data generated or analyzed during this study are included in this published article or available from the corresponding author on reasonable request.

\section{Authors' contributions}

$\mathrm{MJ}$ designed and performed the experiments, participated in the interpretation of data, and wrote manuscript. SMA, MJ, KM, MHB performed the biological experiments, interpreted the data, and wrote the manuscript. All the authors read and approved the final manuscript.

\section{Ethics approval and consent to participate}

This research was carried out in accordance with the ethical guidelines of research on the experimental animals of the National Ethics Committee in Biomedical Research of the Islamic Republic of Iran.

\section{Consent for publication}

Not applicable.

\section{Competing interests}

The author declares that he has no competing interests.

\section{References}

1.Jemal A, Siegel R, Ward E, Hao Y, Xu J, Thun MJ. Cancer statistics, 2009. CA Cancer J Clin. 2009;59:225-49. 
2.Institute NC. Breast Cancer. Cancer Stat Fact Sheet: Cancer of the Breast. 2015.

3. Criscitiello C, Esposito A, De Placido S, et al. Targeting fibroblast growth factor receptor pathway in breast cancer. Curr Opin Oncol. 2015; 27(6): 452-456.

4. Turner $\mathrm{N}$ and Grose R. Fibroblast growth factor signalling: from development to cancer. Nat Rev Cancer .2010; 10(2): 116-129.

5.Owonikoko TK, Arbiser J, Zelnak A, Shu HK, Shim H, Robin AM, et al. Current approaches to the treatment of metastatic brain tumours. Nat Rev Clin Oncol. 2014;11:203-22.

6.Spitale A, Mazzola P, Soldini D, Mazzucchelli L, Bordoni A. Breast cancer classification according to immunohistochemical markers: clinicopathologic features and short-term survival analysis in a population-based study from the South of Switzerland. Ann Oncol. 2009;20:628-35.

7.Strieter RM, Kunkel SL, Bone RC. Role of tumor necrosis factor-alpha in disease states and inflammation. Crit Care Med. 1993;21:S447-63.

8.Yan D, Qin N, Zhang H, Liu T, Yu M, Jiang X, et al. Expression of TNF-alpha leader sequence renders MCF-7 tumor cells resistant to the cytotoxicity of soluble TNF-alpha. Breast Cancer Res Treat. 2009;116:91-102.

9. Thundimadathil J. Cancer treatment using peptides: current therapies and future prospects. J Amino Acids. 2012;2012:967347.

10. Jafarzadeh M, Mousavizadeh K, Taghi Joghataei M, Hashemi Bahremani M, Safa M, Asghari SM. A Fibroblast Growth Factor Antagonist Peptide Inhibits Breast Cancer in BALB/c Mice. Open Life Sci. 2018; 13: $348-354$

11. Ramos S. Cancer chemoprevention and chemotherapy: dietary polyphenols and signaling pathways. Mol nutr food res. 2008; 52(5):507-26.

12. Gamet-Payrastre L, Manenti S, Gratacap MP,Tulliez J, Chap H, Payrastre B. Flavonoids and the inhibition of PKC and PI 3-kinase. Gen Pharmacol.1999; 32(3):279-86.

13. West K A, Castillo S S, Dennis A P. Activation of the PI3K/Akt pathway and chemotherapeutic resistance. Drug Resist Updates. 2002; 5:234-248.

14. Williams R J, Spencer J P. E, Rice-Evans C. Flavonoids: antioxidants or signalling molecules.Free Radical Biol Med. 2004; 36(7): 838 - 849.

15. Osaki M, Oshimura M, Ito H. PI3K-Akt pathway: its functions and alterations in human cancer.Apoptosis. 2004; 9(6):667-76. 
16. Chang F, Lee J, Navolanic P, Steelman L, Shelton J, Blalock W, et al. Involvement of PI3K/Akt pathway in cell cycle progression, apoptosis and neoplastic transformation: a target for cancer chemotherapy. Leukemia. 2003; 17(3):590-603.

17. Vivanco I, Sawyers CL. The phosphatidylinositol 3-Kinase AKT pathway in human cancer. Nat Rev Cancer. 2002; 2(7):489-501.

18. Vara JÁF, Casado E, de Castro J, Cejas P, Belda- Iniesta C, González-Barón M. PI3K/Akt signaling pathway and cancer. Cancer treat rev.2004; 30(2):193-204.

19. Greten FR, Karin M. The IKK/NF-kappaB activation pathway-a target for prevention and treatment of cancer. Cancer Lett. 2004; 206(2):193- 9.

20. Lee $\mathrm{CH}$, Jeon YT, Kim SH, Song YS. NF-KB as a potential molecular target for cancer therapy. Biofactors. 2007; 29(1):19-35.

21. Manna SK, Aggarwal RS, Sethi G, Aggarwal BB, Ramesh GT. Morin (3, 5, 7, 2', 4'-Pentahydroxyflavone) abolishes nuclear factorkappaB activation induced by various carcinogens and inflammatory stimuli, leading to suppression of nuclear factor-kappaB-regulated gene expression and up-regulation of apoptosis. Clin Cancer Res.2007; 13(7):2290-7.

22. Ghorbani A, Nazari M, Jeddi-Tehrani M, Zand H. The citrus flavonoid hesperidin induces p53 and inhibits NF-kappaB activation in order to trigger apoptosis in NALM-6 cells: involvement of PPARgammadependent mechanism. Eur J Nutr.2012; 51(1):39-46.

23. Braun T, Carvalho G, Fabre C, Grosjean J, Fenaux P, Kroemer G. Targeting NF-kappaB in hematologic malignancies. Cell Death Differ. 2006; 13(5):748-58.

24. Easton J, Houghton P. mTOR and cancer therapy. Oncogene. 2006; 25(48):6436-46.

25. Memmott R.M, Dennis P.A. Akt-dependent and - independent mechanisms of mTOR regulation in cancer. Cellular Signal. 2009; 21(5): 656-664.

26.Folkman J. What is the evidence that tumors are angiogenesis dependent? J Natl Cancer Inst. 1990;82:4-6.

27.Folkman J. Tumor angiogenesis: therapeutic implications. New england journal of medicine. 1971;285:1182-6.

28.Kummalue T. Molecular mechanism of herbs in human lung cancer cells. J Med Assoc Thai. 2005;88:1725-34.

29.Eichhorn ME, Kleespies A, Angele MK, Jauch KW, Bruns CJ. Angiogenesis in cancer: molecular mechanisms, clinical impact. Langenbecks Arch Surg. 2007;392:371-9. 
30.Stupp R, Hegi ME, Neyns B, Goldbrunner R, Schlegel U, Clement PM, et al. Phase I/lla study of cilengitide and temozolomide with concomitant radiotherapy followed by cilengitide and temozolomide maintenance therapy in patients with newly diagnosed glioblastoma. J Clin Oncol. 2010;28:2712-8.

31.Andersen MH, Junker N, Ellebaek E, Svane IM, Thor Straten P. Therapeutic cancer vaccines in combination with conventional therapy. J Biomed Biotechnol. 2010;2010:237623.

32.Li Q, Gao S, Yu Y, Wang W, Chen X, Wang R, et al. A novel bFGF antagonist peptide inhibits breast cancer cell growth. Mol Med Rep. 2012;6:210-4.

33. Makarevich PI, Rubina KA, Diykanov DT, Tkachuk VA, Parfyonova YV. [Therapeutic Angiogenesis Using Growth Factors: Current State and Prospects for Development]. Kardiologiia. 2015; 55:59-71.

34.Saini K, Loi Sh, Azambuja E ,Metzger-Filho O, Lamba Saini M, Ignatiadis M, Dancey J, Piccart-Gebhar MJ, Targeting the PI3K/AKT/mTOR and Raf/MEK/ERK pathways in the treatment of breast cancer,Cancer treatment ,volume 39,issue 8 ,pages 935-946

35. Flaherty, K. T. et al. Inhibition of mutated, activated BRAF in metastatic elanoma. N. Engl. J. Med. 363, 809-819 (2010).

36. Flaherty, K. T. et al. Improved survival with MEK inhibition in BRAF-mutated melanoma. N. Engl. J. Med. 367, 107-114 (2012).

37. Wortzel, I. \& Seger, R. The ERK cascade: distinct functions within various subcellular organelles. Genes Cancer 2, 195-209 (2011).

38. Keshet, Y. \& Seger, R. The MAP kinase signaling cascades: a system of hundreds of components regulates a diverse array of physiological functions.Methods Mol. Biol. 661, 3-38 (2010).

39. Morrison, D. K. MAP kinase pathways. Cold Spring Harb. Perspect. Biol. 4, 1-5

(2012).

40. Plotnikov, A., Zehorai, E., Procaccia, S. \& Seger, R. The MAPK cascades:Signaling components, nuclear roles and mechanisms of nuclear translocation. Biochim. Biophys. Acta 1813, 1619-1633 (2011).

41. Osborne, J. K., Zaganjor, E. \& Cobb, M. H. Signal control through Raf: in sickness and in health. Cell Res. 22, 14-22 (2012).

42.Plotnikov A, Flores k, Rachline G, Zehorai E, Kapri-Pardes E, Berti D.A, Hanoch T, Besser M , Seger R, The nuclear translocation of ERK1/2 as an anticancer target,nature communications,2018,1-11

\section{Figures}




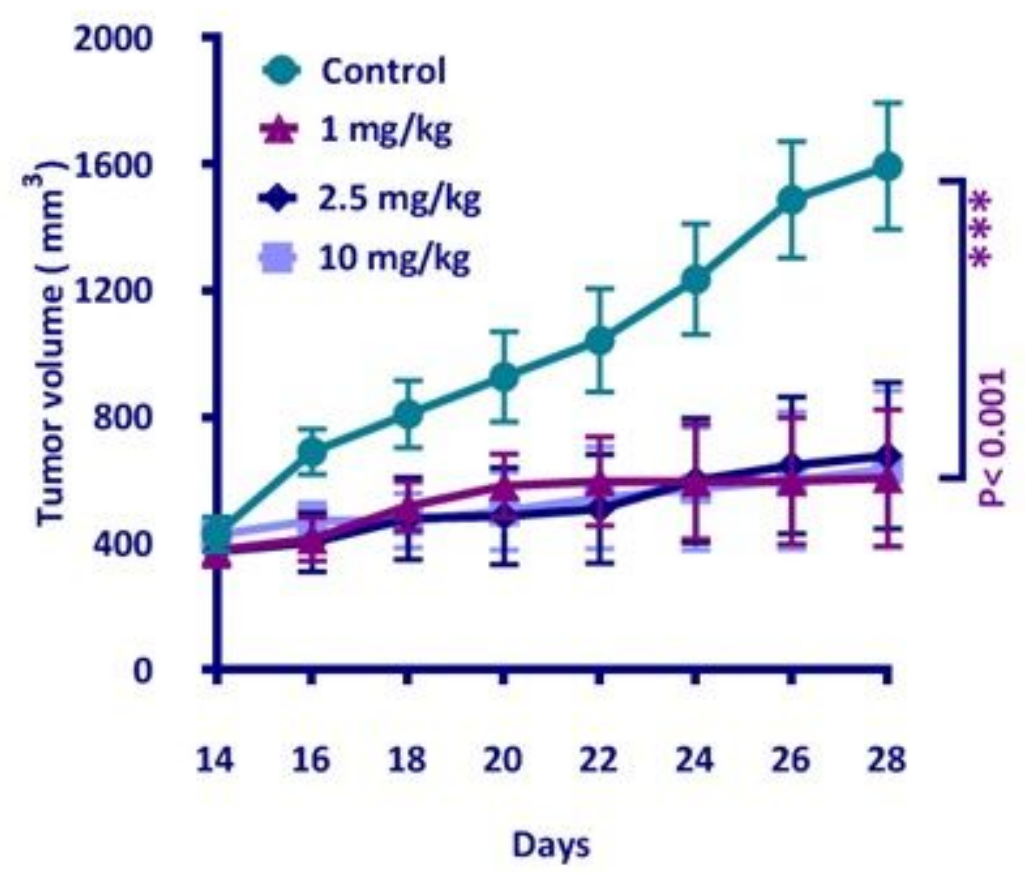

Figure 1

The antitumor impact of bFGF peptide in reversion of 4T1-MCT. Mice $(n=10)$ were subjected to ectopic implantation by $4 T 1$ cells and treatment with $1,2.5$, and $10 \mathrm{mg} / \mathrm{kg}$ of the peptide during 14 days. The animals in the negative and positive control groups received injections by PBS, respectively.

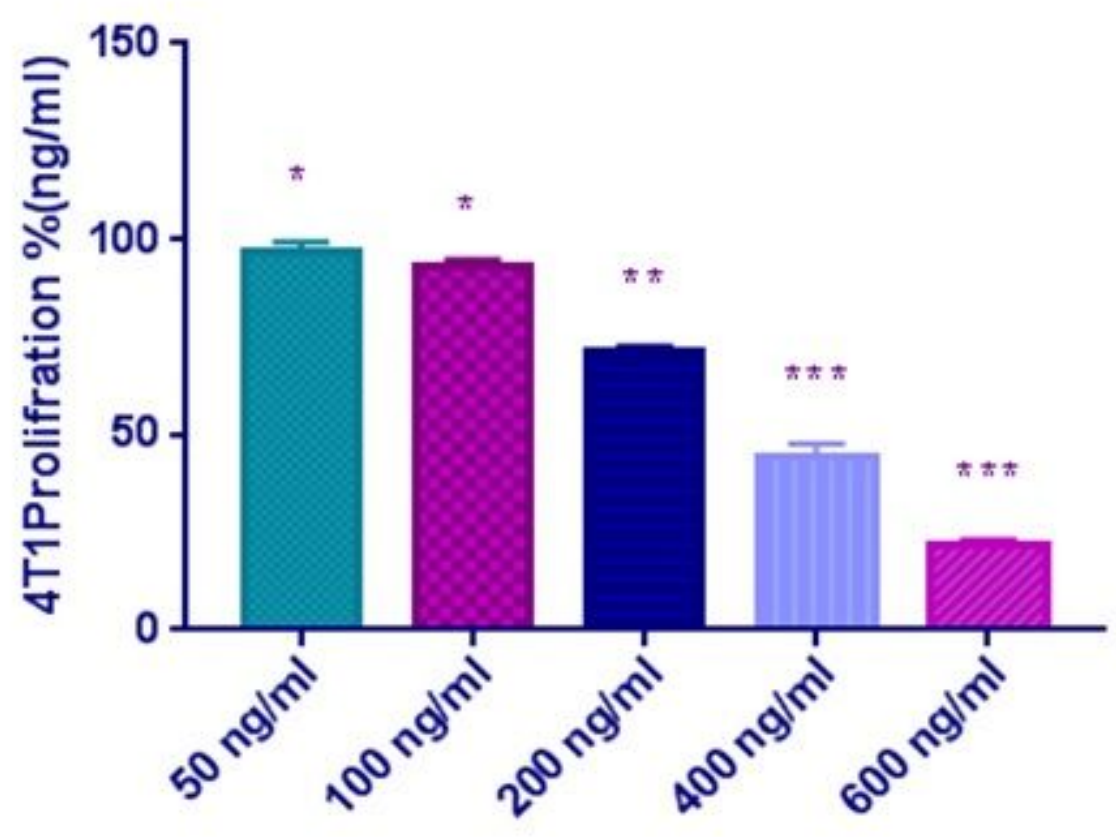

Figure 2

Cell multiplication graphics established with MTT test incubated with the peptide (50 to $600 \mathrm{ng} / \mathrm{ml})$ and $20 \mathrm{ng} / \mathrm{ml}$ of rhbFGF for $24 \mathrm{~h}$. Symbol *denotes examples of statistically significant cases compared to 
peptide using one-way ANOVA $(P<0.05)$ with Tukey's mean comparison.

CD 31

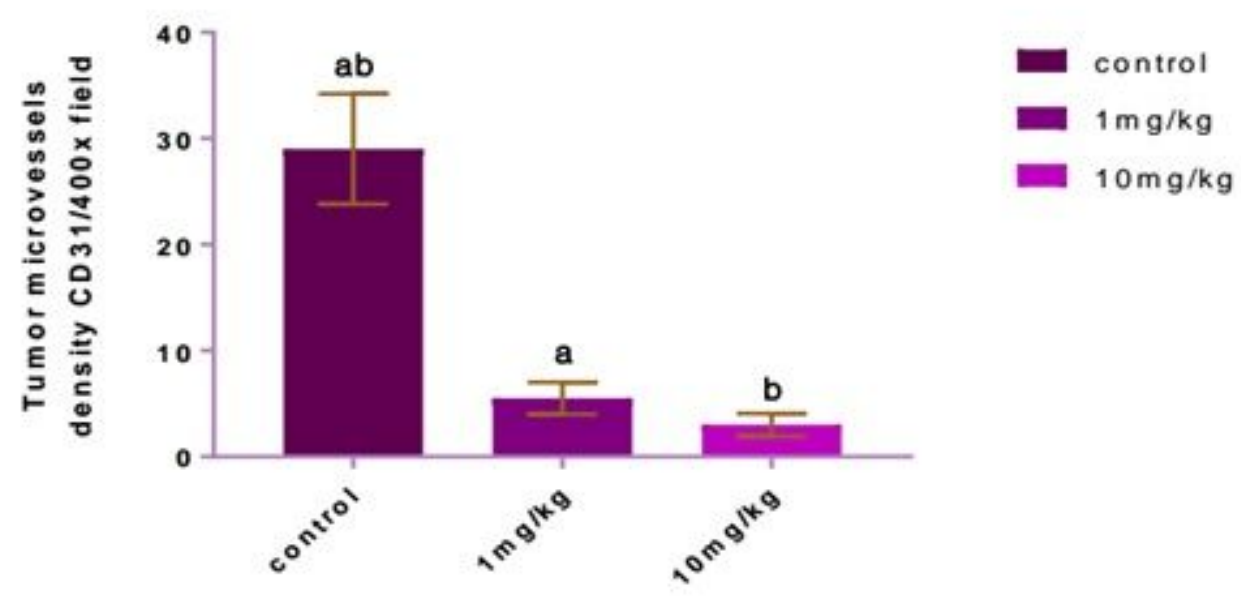

\section{Figure 3}

Effect of Fibroblast Growth Factor Peptide Antagonist on Mouse Model Breast Tumor through ERK/MAPK and PI3K/AKT Signaling Pathways in 4T1 tumor. Tumors were stained by Immunohistochemical. A demonstrative image is depicted for every treatment group in individual cases. TUNEL positive cells were determined by positive (brown) cell count $\times 100 /$ total cell count in 10 chosen at random in every tumor sample $(P \leq 0.05)$.

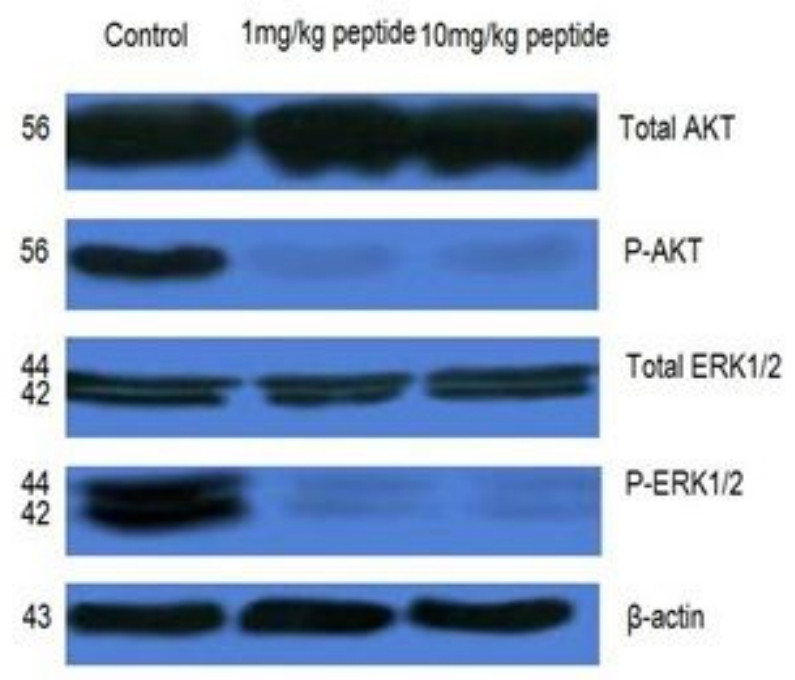

Figure 4

Western blot assay was performed for ERK, PERK, AKT, and PAKT expression levels together with $\beta$-actin as loading control from tumors in every control and $1 \mathrm{mg} / \mathrm{kg}, 10 \mathrm{mg} / \mathrm{kg}$ peptides treatment groups 
described in materials and methods. In each case, the western blot bands presented are similar. Relative levels of $\mathrm{p}-\mathrm{AKT} / \mathrm{AKT}$ and p-ERK1/2/ERK1/2 were assessed by ImageJ.

140
- Total AKT
QP-AKT IITOtal ERK1/2
DP.ERK1/2

120

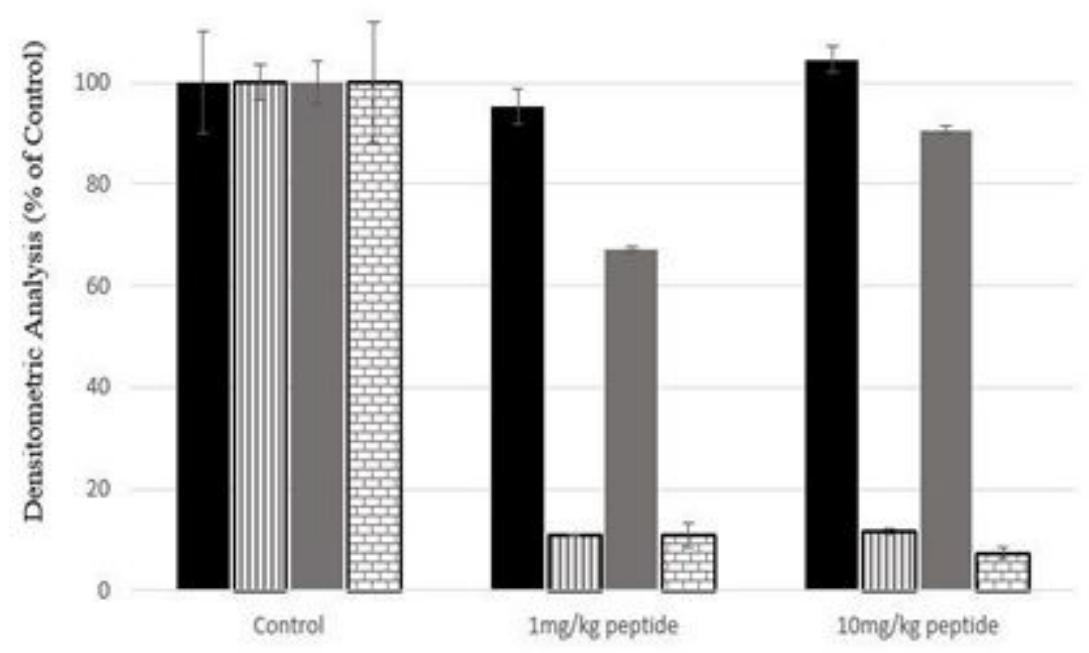

Figure 5

The results showed that the engineered peptide significantly reduced the expression of the phosphorylated forms of ERK, AKT ( $P \leq 0.05)$ and changes in the ERK and AKT expression levels were not significant. The bar chart displays values obtained using Prism 6, representing mean $\pm S E M ; n=6, P \leq 0.05$, One-way ANOVA; ns, non-significant. 